\title{
Uso do Cisco Packet Tracer como ferramenta no ensino-aprendizagem de Redes de Computadores no IFRN - Campus Mossoró
}

Rodrigo Ronner Tertulino da Silva

Instituto Federal de Educação Ciência e Tecnologia do Rio grande do Norte (IFRN)

Campus Mossoró

(rodrigo.tertulino@ifrn.edu.br)

Celina Leite de Oliveira
Instituto Federal de Educação Ciência e Tecnologia do Rio grande do Norte (IFRN)
Campus Mossoró
(celinaleiteo@hotmail.com)
Claudio Peixoto da Silva
Instituto Federal de Educação Ciência e Tecnologia do Rio grande do Norte (IFRN)
Campus Mossoró
(claudio-peixoto12@hotmail.com)
Beatriz Costa Couto
Instituto Federal de Educação Ciência e Tecnologia do Rio grande do Norte (IFRN)
Campus Mossoró
(beatrizcostac@hotmail.com)

Resumo: Este trabalho tem por objetivo investigar as contribuições do uso de softwares simuladores de redes, mais especificamente o Cisco Packet Tracer, como ferramenta no ensinoaprendizagem da disciplina de Redes, no IFRN - Campus Mossoró. A análise da pesquisa ocorre por meio das informações colhidas a partir da aplicação de um questionário destinado aos alunos do curso de Informática, nas modalidades técnico integrado e subsequente, com cunho qualiquantitativa.

Palavras-Chave: Redes de computadores; ensino-aprendizagem; softwares simuladores.

The use of cisco Packet Tracer as a tool in teaching-learning of Computer Networks in IFRN Campus Mossoró

Abstract: The objective of this paper is to investigate the contributions of using network simulator software specifically the Cisco Packet Tracer as a teaching-learning tool in the Networking discipline at IFRN-Campus Mossoró. An analysis of the research through the information gathered from the application of a questionnaire for Informatics course students in the integrated and subsequent technical modalities with qualitative-quantitative character.

Keywords: Computer networks; teaching-learning; software simulators. 


\section{INTRODUÇÃO}

Os métodos de ensino-aprendizagem para a construção de todo um sistema educacional e sua real eficácia é um tema muito discutido, principalmente no Brasil, já que o sistema de ensino atual é defasado e de acordo com pesquisas como o Censo Escolar - um levantamento de informações estatístico-educacionais relativas à Educação Básica, em seus diferentes níveis (educação infantil, ensino fundamental e ensino médio) e modalidades (ensino regular, educação especial e educação de jovens e adultos) - não está nem perto de alcançar seu principal objetivo que é o de que o aluno aprenda. Segundo Lacanallo et al. (2016), essa é uma questão muito complexa e envolve muita discussão já que durante o processo diversos fatores políticos, científicos, econômicos e tecnológicos influenciam, podendo ser de cunho positivo ou negativo.

Diante da realidade vivida não somente no Brasil como em todo o mundo, não se pode deixar de lado também a influência que a tecnologia tem em todos os âmbitos da vida de uma pessoa, não somente pessoal como também acadêmico. Portanto, com o avanço tecnológico surgiram novas maneiras de se transmitir determinado conhecimento, ou seja, novos métodos de ensino em que ferramentas antes que não existiam para o auxílio ao conhecimento podem ser utilizadas, um exemplo muito comum são as lousas digitais e também livros didáticos que podem ser acessados em computadores, tablets e até mesmo por smartphones.

Da mesma maneira que surgiram novos métodos, surgiram também novas áreas do conhecimento, como matérias técnicas relacionadas ao ensino de redes, por exemplo. Tomando como base mais especificamente o ensino de redes no curso de Informática, o acesso a laboratórios com equipamentos que servem como ferramentas de ensino, ou seja, que sejam equipados suficientemente com o necessário, não é algo muito comum já que instituições públicas de ensino como o IFRN - Campus Mossoró não tem condições de possuir toda a infraestrutura necessária, pois o custo é muito alto e muitas vezes não é tido como prioridade já que a matéria de redes é uma das diversas outras matérias técnicas lecionadas, ou seja, não há uma grande preocupação por parte das instituições públicas sobre o ensino específico dessa matéria. 
Tendo em vista problemas como o já citado, uma maneira de contornar e suprir a necessidade dos estudantes é com a utilização de softwares simuladores que vêm sendo cada vez mais aperfeiçoados e melhorados, reproduzindo a realidade de maneira muito eficaz e propiciando um ensino de qualidade para todos os estudantes do curso de Informática, que acabam não sendo prejudicados pela realidade em que vivem.

Essa prática foi adotada no IFRN - Campus Mossoró na disciplina de Redes de Computadores com a utilização do Cisco Packet Tracer. O presente estudo propõe analisar as contribuições da utilização deste software educativo como ferramenta de ensino-aprendizagem no ensino de redes, identificando também as desvantagens no processo de utilização de acordo com a visão dos alunos, buscando sugestões de melhora e refletindo-se assim a importância desses softwares simuladores na comunidade acadêmica. Tendo a seguinte questão norteadora: qual a contribuição da utilização do Cisco Packet Tracer para o ensino de redes no IFRN - Campus Mossoró e o que pode ser melhorado?

\section{REFERENCIAL TEÓRICO}

\subsection{A importância da Informática na educação}

A sociedade, atualmente, vem apoderando-se diariamente de inovações tecnológicas, com isso a informática vem adquirindo cada vez mais relevância na vida das pessoas, pois, a mesma serve como uma assistência para a sociedade. Quando se buscava a informação, uma das primeiras ações era ir direto às fontes bibliográficas (material impresso), ou às fontes pessoais (oralidade).

Com o surgimento da tecnologia, na busca de informações, recorreu-se ao computador que, por meio da internet, é um facilitador indiscutível do acesso à informação, mas nem sempre encontrar-se o que procura, visto que, na internet há uma infinidade de informações disponibilizadas sendo muitas delas irrelevantes para o resultado da busca.

Para Sanches (2008), o avanço tecnológico tem influenciado muito nossa vida, ditando modos e comportamentos, criando inovações e conhecimentos diversos e aguçando nossa curiosidade. Em comparação com o modo de vida de 
cerca de dez anos, percebe-se o quanto passamos a ser exigentes com a execução das tarefas rotineiras, por estarmos acostumados a ter acesso à informação de uma forma rápida e interativa.

A informática, no âmbito escolar, tem grande significado tanto no aprendizado do aluno quanto na metodologia de ensino do professor, pois, os mesmos em geral, podem usar computadores, equipamentos audiovisuais e outros meios tecnológicos para deixar suas aulas mais dinâmicas fazendo o aluno se aprimorar melhor do que Ihe é ensinado. Com isso, hoje, a informática exerce um papel importante na educação e, para alcançar resultados satisfatórios e suprir a necessidade que a sociedade atual vive, se faz necessário que o professor seja um profissional com particularidades positivas, pois, seu papel é fundamental na inclusão da informática na educação.

Zaragoza e Silva $(2008$, p. 24, 25) enfatizam a presença do professor como facilitador, ao fazer interagir os conteúdos de suas disciplinas com os alunos, utilizando o computador como mediador.

Através da avaliação dos resultados obtidos com o uso das ferramentas disponibilizadas para alunos e professores das instituições, pode-se chegar à seguinte conclusão: se realmente a eficiência da informática no âmbito escolar está sendo eficaz no ensino-aprendizado do educando e do educador.

\subsection{Simuladores de redes de computadores}

Éde conhecimento geral que a tecnologia se faz necessária em todos as áreas. E mais do que isso, no ramo da computação é fundamental trabalharmos com tecnologias que nos possibilitam simular trabalhos já realizados ou em construção. A simulação é algo crucial na análise e implementação de sistemas de rede de computadores, levando em conta todas as dificuldades de ter um laboratório real. A realização de algumas tarefas nos simuladores de redes coloca os alunos 0 mais próximo possível de suas experiências profissionais posteriormente.

Apostando nisso, a utilização dos simuladores vem crescendo nas instituições e universidades de forma significativa já que nem todos disponibilizam recursos tão altos para a construção de um ambiente real com tantas variedades de ferramentas. Outro ponto que vale ressaltar sobre os simuladores é que, permitem testar o 
desempenho de protocolos em várias redes e ambientes, onde em um laboratório real ou uma empresa talvez fosse impossível uma preparação como ocorre nos simuladores por questão de tempo. Assim, facilitam a execução dos protocolos em vários cenários.

Existem vários simuladores de redes de computadores, alguns usados para auxiliar pesquisas e outros para testes, buscando aprimorar equipamentos ou programas antes de lançá-los no ambiente real. Utilizaremos os simuladores para práticas educacionais, pensando no aprendizado em todas as suas vertentes, contando com a importância das práticas e uso de todas ferramentas vistas na teoria. O Cisco Packet Tracer foi o simulador usado nas aulas práticas, já despertando um interesse nesse ambiente virtual.

\subsection{A importância da utilização do Cisco Packet Tracer}

Atualmente, o uso de simuladores na disciplina de rede de computadores é de grande importância para o desenvolvimento do estudante, visto que algumas instituições de ensino não dispõem de laboratórios bem estruturados e equipados, que possam ser adequados para uma aula prática da disciplina, fazendo-se necessário o uso de simuladores, uma vez que desempenham um papel importante na tarefa de desenvolver, analisar e aperfeiçoar atividades plenas, com caráter temático no conteúdo específico da disciplina.

Segundo a Cisco, "O Packet Tracer ajuda os alunos a criarem seus próprios "mundos de rede" virtuais para exploração, experimentação e explicação de conceitos e tecnologias de rede" (CISCO NETWORKING ACADEMY, 2010).

O Packet Tracer, além de ser um software de simulação de redes sem custo algum para download e instalação, é uma ferramenta que se utiliza também para fins acadêmicos. O uso deste software possibilita gerar tráfego na rede criada, acompanhar visualmente os pacotes e frames e simular aplicações específicas, sendo um simulador bastante interativo com o usuário, em que o mesmo oferece alguns outros recursos, como autoria, avaliação e colaboração, facilitando o ensino e aprendizagem de conceitos tecnológicos para o aluno. 


\section{METODOLOGIA}

A pesquisa é uma ferramenta de investigação e avaliação que busca propor respostas para indagações de diversas áreas do conhecimento, por conseguinte, é um ato que proporciona o avanço da ciência, ou seja, causa mudanças nas áreas do saber, que passam a se renovar, e refletem assim na sociedade, propiciando o seu desenvolvimento (GOMES, 2017). Assim, o presente trabalho busca, por meio de uma pesquisa e uma análise quali-quantitativa, investigar as percepções dos alunos, bem como as vantagens e desvantagens da utilização de simuladores digitais no ensino da matéria de Redes de Computadores no IFRN - Campus Mossoró de acordo com a visão dos discentes.

Para isso, foram realizadas pesquisas bibliográficas e uma pesquisa de campo, em que foram utilizados questionários eletrônicos criados a partir do Google Forms, uma plataforma online disponibilizada pelo Google para montagem e aplicação de questionários online. Uma vez que se procura investigar um grupo particular pertencente ao IFRN - Campus Mossoró, foi optado por este tipo de pesquisa, pois se preocupa com um nível de realidade que não pode ser somente quantificado (MINAYO, 2012 apud GOMES, 2017). Assim, a partir da análise das opiniões dos alunos quanto aos pontos negativos e positivos, buscamos identificar se o ensino alternativo funciona de maneira eficaz, além de listarmos sugestões dos mesmos para um ensino cada vez melhor.

A pesquisa realizada teve como universo os alunos do curso de Informática que estão cursando os $3^{\circ}$ e $4^{\circ}$ anos na modalidade integrada e os que estão cursando na modalidade subsequente, pois são as turmas que cursam ou já cursaram a disciplina de Redes de Computadores, utilizando-se uma amostra de 100 por cento. Foram aplicados questionários com questões fechadas que permitiram a coleta de informações necessárias sobre o tema em questão. Desse modo, pode-se compreender de forma mais clara as percepções dos alunos acerca da forma de ensino.

O questionário utilizado para a realização da pesquisa contou com 6 perguntas, sendo todas objetivas, envolvendo perguntas variadas que questionam as impressões que os alunos têm da utilização da ferramenta, quais suas dificuldades na utilização, quais os pontos positivos identificados por eles e como 
eles enxergam maneiras melhores de aprenderem o conteúdo, dentre outras desse caráter.

Éessencial que a escolha da abordagem esteja a serviço do objeto da pesquisa, e não o contrário, com o propósito de daí tirar o melhor possível, os saberes desejados. Parece haver um consenso, pois, quanto à ideia de que as abordagens qualitativas e quantitativas devem ser encaradas como complementares, em vez de mutuamente concorrentes (MALHOTRA, 2001; LAVILLE \& DIONNE, 1999 apud OLIVEIRA, 2011, p. 27). Assim, com a utilização deste método de pesquisa que engloba ambas, pesquisa qualitativa e quantitativa, após a aplicação dos questionários as informações coletadas foram analisadas e estruturadas por meio de uma análise textual descritiva e exposição de alguns gráficos com os resultados das respostas, para assim se alcançar os objetivos da presente pesquisa.

\section{RESULTADOS ALCANÇADOS E DISCUSSÕES}

Diante do exposto, apresenta-se neste tópico os resultados da pesquisa de cunho quali-quantitativa, realizada com a exposição de alguns dos gráficos das respostas coletadas e análise descritiva destes. Foi aplicado o questionário para um total de 70 alunos, sendo 56 da modalidade integrada e 14 da modalidade subsequente, em que se pôde compreender de maneira geral as percepções dos alunos acerca da utilização do Cisco Packet Tracer, além da coleta de algumas sugestões de melhora.

Para a averiguação das percepções dos alunos e coleta das sugestões, foram feitas algumas perguntas sobre o que os alunos achavam da utilização do simulador nas aulas, o nível de auxílio do simulador na compreensão da matéria pelos alunos, quais pontos negativos e positivos podiam ser identificados, além de uma pergunta na qual os alunos foram convidados a avaliar de maneira geral o simulador e também sugerirem opções de melhora.

Por meio da análise dos resultados do questionário, foi percebido que a maioria dos alunos considera a utilização do simulador algo muito bom e necessário, 
em que quase $95 \%$ do total de respostas se classificaram entre Muito Bom e Bom, refletindo como a aceitação do simulador é positiva e bem vista pelos alunos.

Outra informação notada está relacionada com o auxílio ou não do simulador na compreensão dos conteúdos da matéria de Redes de Computadores. Neste caso, mais de $97 \%$ do total de respostas foram positivas, reverberando a importância da utilização do simulador no processo de ensino-aprendizagem, sendo muitas vezes um facilitador da apreensão do conteúdo pelo aluno.

Para se analisar de uma perspectiva mais geral e subjetiva, foi questionado também quais os pontos negativos identificados pelos alunos, no simulador. Apesar das avaliações positivas observadas em outros questionamentos, neste caso, os resultados se mostraram mais equilibrados. Aproximadamente $50 \%$ do total de respostas se classificaram como negativas à existência de pontos negativos, sendo na outra metade apontados pelos alunos algumas desvantagens durante o processo de utilização, principalmente com relação ao manuseio e à interface gráfica do software, podendo-se apreender que apesar de eficiente na função de simular uma realidade virtual, ainda apresenta déficits que podem ser estudados para se buscar soluções e assim ajudar ainda mais aos alunos, como mostra na figura 1.

\section{Figura 1 - Encontrou algum ponto negativo no simulador? Se sim, qual?}

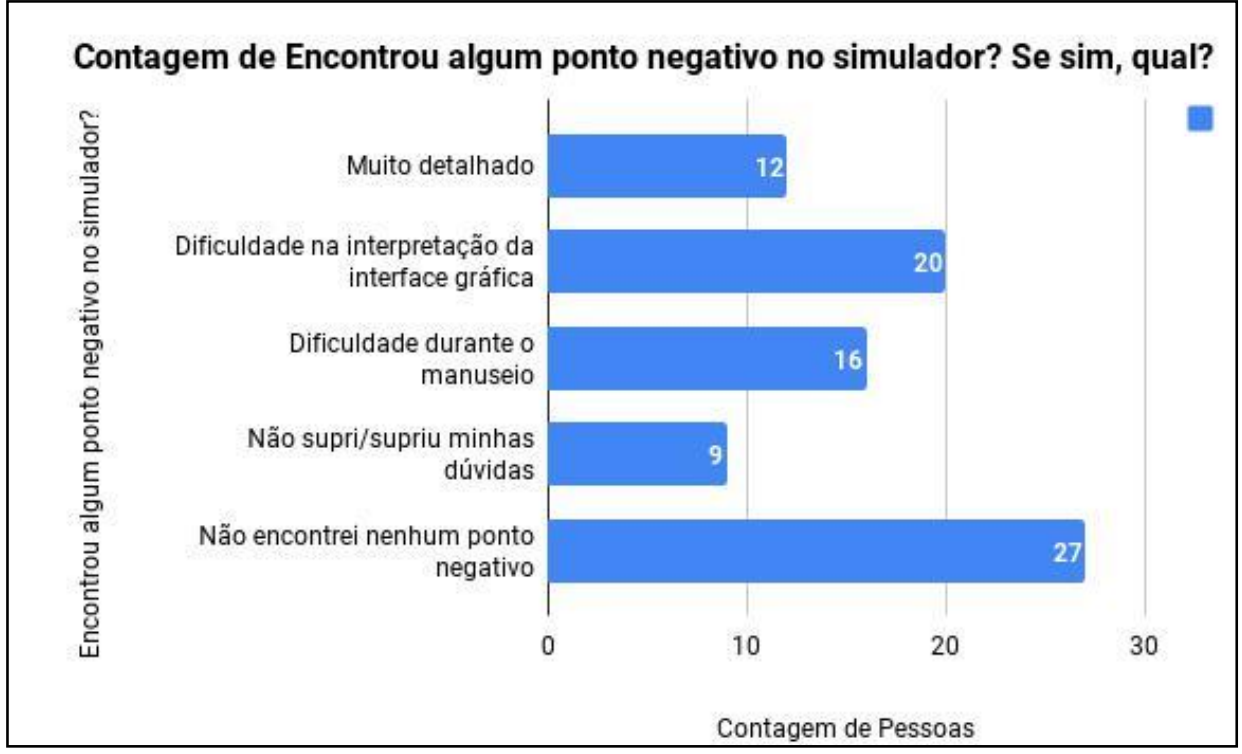

Fonte: Autores

Da mesma forma que foram questionados sobre pontos negativos, os alunos também foram questionados sobre quais os pontos positivos encontrados por eles, 
no simulador, em que na maioria das respostas se refletiu o auxílio do simulador no processo de apreensão dos conteúdos, principalmente do ponto de vista prático, ou seja, por ser um método de ensino diferente e inovador os alunos se mostraram mais interessados em aprender, fugindo dos métodos de ensino padrões que tornam muitas vezes as aulas ociosas, despertando maior interesse dos alunos e também maior facilidade em absorver o conteúdo ministrado, apesar, da falta de instrumentos específicos da área para a realização de práticas, mostrado na figura 2.

Figura 2 - Encontrou algum ponto positivo no simulador? Se sim, qual?

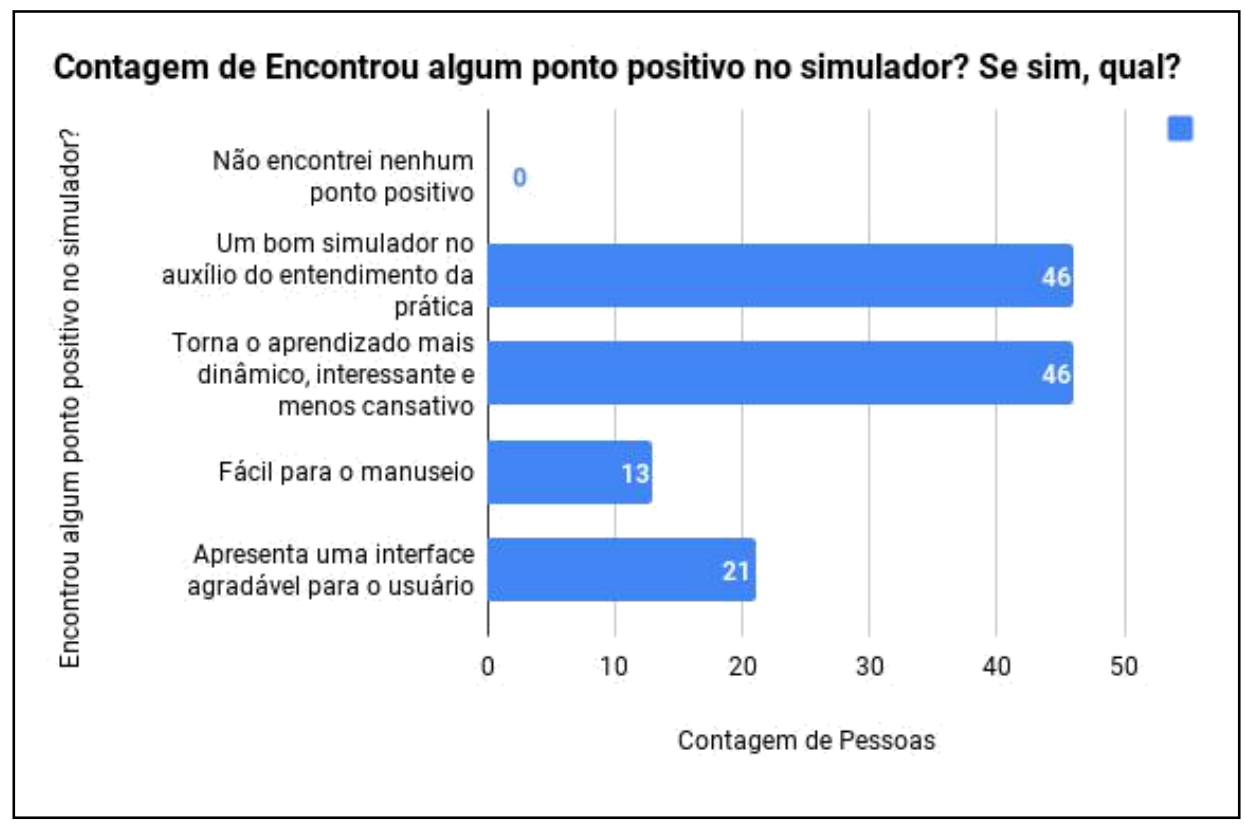

Fonte: Autores

Quando questionados sobre o que achavam que poderia ser melhorado no software, as respostas também se dividiram, em que cerca de metade dos alunos afirmaram estar satisfeitos com o software sem necessidade de mudanças e já a outra parte sugeriu que a interface poderia ser alterada para se tornar ainda mais fácil o manuseio, e consequentemente mais fácil a compreensão dos processos práticos simulados. Mais uma vez, entrando em questão essa desvantagem do simulador relacionada à interface, algo de destaque que reflete a necessidade de melhoria neste ponto, ilustrado na figura 3. 
Figura 3 - Na sua opinião, o que poderia ser melhorado tanto no software ou na sua utilização para melhor compreensão da disciplina?

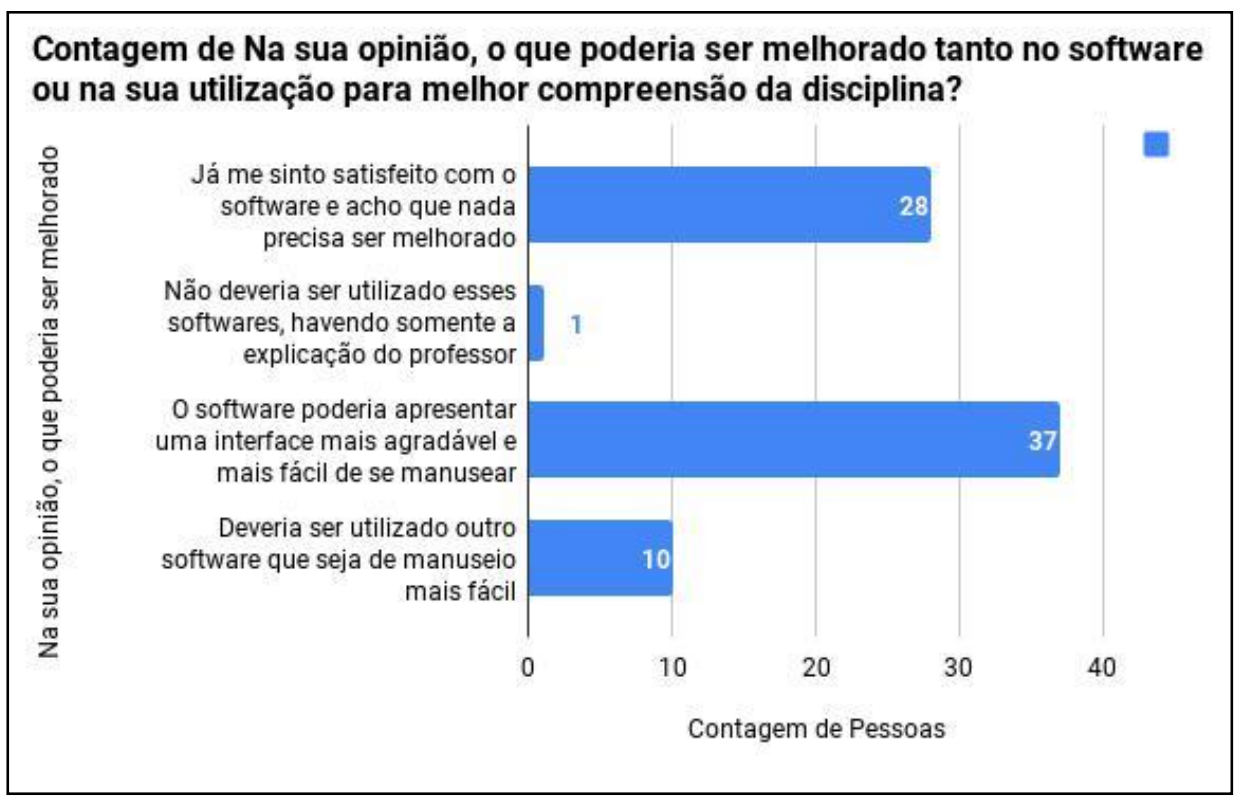

Fonte: Autores

A fim de termos uma visão mais geral da percepção dos alunos, que englobasse tanto suas avaliações de pontos negativos como positivos, foi proposto que estes dessem uma nota ao simulador em que se obteve como média a nota 8 , refletindo mais uma vez que, do ponto de vista geral, a maioria dos alunos avalia de maneira positiva e proveitosa a utilização do Cisco Packet Tracer no Campus Mossoró, uma ferramenta nova e não convencional utilizada no processo de ensino aprendizagem, mas que vem se mostrando eficaz.

\section{CONSIDERAÇÕES FINAIS}

Diante do que foi discutido ao longo desse trabalho, foi possível perceber o quanto a utilização de um simulador computacional é importante numa instituição de ensino, quando bem direcionado por um docente, já que proporciona aos alunos um ótimo entendimento da prática. No entanto, percebe-se, também, que é necessário o conhecimento por parte do professor para a existência deste tipo de prática que não é muito comum.

A análise quali-quantitativa dos questionários aplicados para a realização dessa pesquisa revelou que os alunos se sentem muito satisfeitos com o simulador 
e que a sua utilização ajuda na apreensão dos conteúdos, mas que além disso torna as aulas menos ociosas sendo uma ferramenta importantíssima no processo de ensino-aprendizagem que é muito precário, principalmente no Brasil.

Outra informação bastante relevante nas respostas é a de que, apesar de ser muito eficiente, o simulador apresenta alguns pontos que precisam ser melhorados, principalmente no que diz respeito à interface gráfica e ao manuseio do simulador, um ponto que precisa ser avaliado e melhorado pelo professor para que o nível de conhecimento dos alunos só possa aumentar.

Por fim, é possível concluir dizendo que, na visão dos alunos do curso de Informática dos $3^{\circ}$ e $4^{\circ}$ anos do nível técnico-integrado do IFRN - Campus Mossoró, juntamente com os alunos do nível técnico subsequente, o simulador desempenha um importante papel para a apreensão dos conteúdos da matéria de Redes de Computadores, já que de acordo com a realidade do Campus não é possível ter uma estrutura física presente. No que se refere às vantagens e desvantagens, a avaliação positiva prevalece sobre a negativa, porém como é algo novo e está em processo de aperfeiçoamento deve-se atentar aos pontos fracos e assim ter um melhor desempenho.

Diante do que foi exposto, espera-se ter contribuído de maneira positiva para a compreensão de o quanto é importante a utilização de simuladores no processo de ensino-aprendizagem, sendo ferramentas de ensino muito eficientes, ganhando grande relevância no diz respeito ao âmbito do ensino da matéria de Redes. Uma prática que não deveria se restringir somente ao Campus Mossoró, como também a todos os outros Campus do IFRN como um todo, que ofertam o curso de Informática e possuem a disciplina de redes na grade curricular, pois, como todos vivenciam a mesma realidade, teria-se um importante efeito e função, contribuindo de forma direta na boa formação dos profissionais pela instituição.

\section{Referências}

CISCO NETWORKING ACADEMY (EstadosUnidos). Cisco Packet Tracer. 2010. Disponível em: <http://www.cisco.com/c/dam/en_us/trainingevents/netacad/course_catalog/docs/Cis o_PacketTracer_AAG.pdf >. Acesso em: 02 de agosto de 2017. 
GOMES, Antônia Camila de Araújo. O papel da biblioteca na formação do leitor: Uma análise das práticas de leitura junto aos alunos do curso de edificações do IFRN-Campus Mossoró. 2017. 18 f. Monografia (Especialização) - Curso de Especialização em Educação e Contemporaneidade, IFRN - Campus Mossoró, Mossoró, 2017.

LACANALLO, L. F. et al. Métodos de ensino e de aprendizagem: uma análise histórica e educacional do trabalho didático. Disponível em: <http://www.histedbr.fe.unicamp.br/acer_histedbr/jornada/jornada7/_GT4\%20 $\mathrm{PDF} / \mathrm{M} \% \mathrm{C}$

9TODOS\%20DE\%20ENSINO\%20E\%20DE\%20APRENDIZAGEM\%20UMA\% 20AN\%C1 LISE\%20HIST\%D3RICA.pdf>. Acesso em: 15 de março de 2017.

OLIVEIRA, Maxwell Ferreira de. Metodologia científica: um manual para a realização de pesquisas em Administração. Catalão: UFG, 2011. 72 p.

SANCHES, V. J. C. Tecnologia para inovações na didática do ensino: Um Estudo de Caso: Lousa Eletrônica. Disponível em: $<$ http://www2.dc.uel.br/nourau/document/?down=742>. Acesso em: 03 de julho de 2017.

ZARAGOZA, C. A. R.; SILVA, E. V. N. A informática e a construção do conhecimento: Interfaces Possíveis e Prática Pedagógica. São Paulo: Universidade Taubaté, 2008. 